\title{
Does correct knowledge about HIV and AIDS lead to safer sexual behaviour? The case of young people in Botswana
}

\author{
Gobopamang Letamo \\ Department of Population Studies, University of Botswana \\ Private Bag UB 00705, Gaborone, Botswana \\ Telephone (267) 3554167, Fax (267) 3185099, letamog@mopipi.ub.bw
}

\section{Abstract}

This article investigates the extent to which acquired correct knowledge about HIV and AIDS prevention and transmission is translated into protective sexual behaviours among young people in Botswana. This research uses a nationally representative sample of the Botswana AIDS Impact Survey (BAIS) conducted in 2004. The sample for the current study was limited to all people aged 10-24 who had completed the individual questionnaire of BAIS and have had sexual intercourse at the time of the survey. Both bivariate and multiple regression analyses are used to investigate the topic.

The results from both bivariate and multivariate analyses indicate that a consistent and significant predictor of safe sex behaviours among young people is the knowledge that something can be done to prevent becoming infected with HIV. In the multivariate analysis, knowledge that people cannot get HIV because of witchcraft is significantly associated with the likelihood to report safe sexual behaviours whilst knowledge that a person cannot get infected with HIV through mosquito bites is significantly associated with decreased odds of reporting safe sexual behaviours. The study concludes that although correct knowledge of HIV/ AIDS prevention and transmission methods does not necessarily translate into safe sexual behaviours, some knowledge of HIV prevention and transmission methods among young people is associated with safe sexual behaviours. There are other predictors of safe sexual behaviours other than HIV-related knowledge of prevention measures. Further research that combines both qualitative and quantitative approaches is needed to clarify the exact nature of how knowledge of HIV and AIDS prevention and transmission influences protective sex behaviours. The research should also explore the role played by these unknown factors in predicting safe sex behaviours.

Keywords: Botswana; young people; HIV/AIDS; sexual behaviour; prevention; transmission.

\section{Résumé}

Cet article examine dans quelle mesure les acquis correcte sur la prévention du $\mathrm{VIH}$ et du SIDA et transmission est traduite en protection des comportements sexuels parmi les jeunes au Botswana. Cette recherche utilise un échantillon 
représentatif au niveau national de le Botswana AIDS Impact Survey (BAIS) menée en 2004. L'échantillon pour l'étude actuelle a été limitée à tous les gens âgés de 10 à 24 ans, qui avait rempli le questionnaire individuel de BAIS et ont eu des relations sexuelles au moment de l'enquête. Les deux bivariée et plusieurs analyses de régression servent à enquêter sur le sujet.

Les résultats des analyses multidimensionnelles tant bivariées indiquent qu'un prédicteur cohérente et significative des comportements safe sex chez les jeunes est la connaissance que quelque chose peut être faite pour empêcher l'infection par le VIH. Dans l'analyse multivariable, connaissance que les personnes ne peut pas obtenir penvent $\mathrm{VIH}$ en raison de la sorcellerie est fortement associé à la probabilité de comportements sexuels sécuritaire de rapport tandis que les connaissances qu'une personne ne peut pas obtenir infectée par le VIH par le biais de piqûres est considérablement associé à odds diminution des rapports des comportements sexuels en toute sécurité. L'étude conclut que, bien que la bonne connaissance des méthodes de prévention et de la transmission du VIH/SIDA ne se traduit pas nécessairement par les comportements sexuels en toute sécurité, certaines connaissances de prévention du VIH et de méthodes de transmission parmi les jeunes est associée à des comportements sexuels en toute sécurité. II existe des autres indicateurs de sécurité des comportements sexuels autres que les connaissances liient au VIH de mesures de prévention. D'autres recherches qui combinent la fois qualitative et quantitative sont nécessaire de préciser la nature exacte du comment connaissance de prévention du VIH et du SIDA et de la transmission influe sur les comportements sexuels de protection. La recherche devrait examiner également le rôle joué par ces facteurs inconnus en prévision des comportements safe sex.

Mots clés : Botswana jeunes ; le VIH/SIDA ; comportement sexuel ; prévention ; transmission.

\section{Introduction}

The HIV/AIDS scourge is increasingly a disease of the young and the most vulnerable. About I 3 per cent of the 15-24 year-old people in Botswana were living with HIV/AIDS in 2004 (Republic of Botswana, 2005). Preventing HIV among young people is at the core of the global response. Although there are various ways HIV infection can be transmitted, the major route of HIV transmission in sub-Saharan Africa is heterosexual intercourse. Sexual activity for the majority of people begins in adolescence. Yet young people remain alarmingly uninformed about the basic facts about HIV and its transmission and prevention. Evidence from some studies (UNICEF, undated) have shown that wherever the spread of HIV is slowing or even declining, it is primarily because young people are being given the tools and means to adopt safe sexual behaviour.

The UNICEF, UNAIDS \& WHO (2002) study found that the vast majority of the world's young people have no idea how HIV/AIDS is transmitted or how to protect themselves from diseases, although the majority of people become sexually active while adolescents. However, in Botswana the majority of young people have a lot of knowledge on transmission routes and 
potential protective measures (Republic of Botswana, 2005). The UN report shows that young people have sex, but often do not have sufficient knowledge to protect them from HIV infection. The report also reflects that many young people also harbour serious misconceptions about how HIV/AIDS is transmitted - a strong indicator that young people are not getting access to the right information. Despite the high levels of knowledge about HIV and AIDS, there are a lot of mixed and opposing messages that often do not reflect the biomedical view on HIV transmission (for instance, explanations of AIDS as God's punishment and a result of pollution). So most people have heard of the biological mechanisms of HIV transmission but do not necessarily accept this and therefore do not necessarily adopt safe sex as defined in biomedical terms.

Several information, education and communications (IEC) activities have been undertaken in the country on the assumption that knowledge leads to positive action. Currently, only $15.4 \%$ of males and $22.1 \%$ of females aged 15 24 years have sufficient HIV/AIDS knowledge and a quarter to a third of the population still harbours myths about HIV transmission (Republic of Botswana, 2006). Republic of Botswana (2006) also argues that high levels of awareness and knowledge has not been sufficient to motivate the adoption of HIV-protective behaviours.

The purpose of this study is to establish the link between correct knowledge of HIV prevention and transmission and the sexual behaviours of young people using an appropriate method of data analysis. This study is important because empirical evidence is needed for both policymaking and the design of appropriate programmes targeted at behaviour change. Programme managers and policy makers need to base their decisions on empirical evidence for their policies and programmes to be effective. The study is expected to discover if indeed correct knowledge of HIV/AIDS prevention and transmission leads to positive sexual behaviour change. It is important to know how effective some of the IEC programmes targeting young people with HIV and AIDS behaviour change interventions are performing and to assess what kinds of interventions need strengthening.

\section{Literature review and theoretical framework}

One of the most commonly used theories for understanding HIV-related sexual risk is the Theory of Reasoned Action (TRA) (Ajzen and Fishbein, 1980) and its extension, Theory of Planned Behaviour (TPB) (Ajzen, 1991). According to both the TRA and TPB, an individual's intention to engage in behaviour (e.g. condom use) is the primary determinant of whether the behaviour occurs (i.e. use condom or have no multiple sexual partners) (Ajzen and Fishbein, 1980). The TRA proposes that intentions are, in turn, influenced by the individual's behavioural beliefs or attitudes about the behaviour and his or her normative beliefs regarding the behaviour (Hutchinson, et al., 2007). The theory states that if people evaluated the suggested behaviour as positive (attitude), and if they think their significant others wanted them to perform the behaviour (subjective 
norm), this results in a higher intention (motivation) and they are more likely to do so (behaviour).

In 1985, Ajzen (1985, 1991) incorporated a third variable, control beliefs, into the model, resulting in the TPB.
Control beliefs refer to individuals' beliefs that they possess the necessary resources, skills and opportunities to perform the behaviour (Madden, Ellen \& Ajzen, 1992).

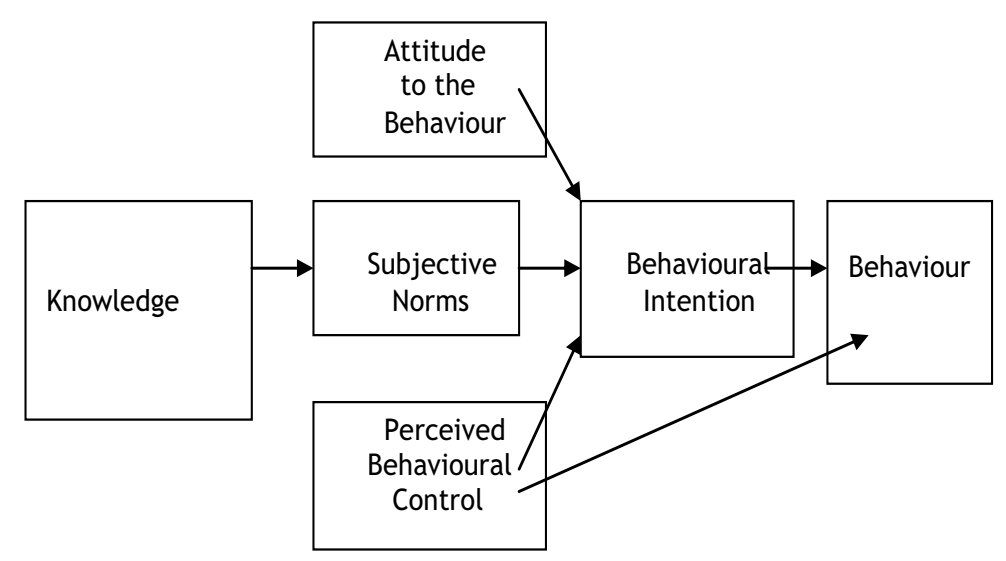

Source: Ajzen, 2006

Figure ITheory of Planned Behaviour

Figure I presents a diagram of the Theory of Planned Behaviour which explains factors influencing the individual's behaviour. Ajzen (2006) defines the concepts used in the theory as follows: Attitude toward behaviour is an individual's positive or negative evaluation of self-performance of the behaviour. Subjective norm is an individual's perception of the social normative pressures or relevant others' beliefs that he or she should or should not perform such a behaviour. Perceived behavioural control is an individual's beliefs about the presence of factors that may facilitate or impede performance of the behaviour and is conceptually related to self-efficacy. Behavioural intention is an indication of an individual's readiness to perform a given behaviour. Behaviour is an individual's observable response in a given situation with respect to a given target.

Ajzen (2006) postulates that the more favourable the attitude toward behaviour and subjective norm and the greater the perceived behavioural control, the stronger the person's intention to perform the behaviour in question should be. Therefore, given a sufficient degree of actual control over the behaviour, people are expected to carry out their intentions when the opportunity arises (Ajzen, 2006). For instance, the use of condoms during sexual intercourse may be a direct function of a person's intention to use a condom during sexual intercourse, although it is also possible that the other partner might not have intended 
to use condoms but passively tolerates the other's decision. Thus respondents might have reported condom use in the last sexual encounter although they themselves might not really have intended to use a condom, just went along with what their sex partner did. The decision to have multiple sexual relationships is a direct function of an individual's intention to do so. Interventions that have addressed perceived self-efficacy and safer sex skill building have been found to be effective in reducing HIV-related sexual risk behaviours (Jemmott et al., 200I). Hutchinson et al. (2007) noted that within the TPB, behavioural, normative, and control beliefs are viewed as the sole determinants of intentions and behaviours and all other factors are viewed as external influences that act through their influence on these three constructs.

\section{Research question}

The research question for this study is: Are young people who have correct knowledge about HIV/AIDS prevention and transmission methods more likely to adopt safer sexual behaviours than those who do not possess correct knowledge about HIV/AIDS prevention and transmission methods?

\section{Data and methods}

The purpose of this study is to establish if correct knowledge about HIV/AIDS prevention and transmission methods encourage young people to adopt safe sexual behaviours. This section discusses the data used for analysis, sample size, measurement of the variables used in the study, the statistical meth- ods used for analysis, and the limitations of the study.

Data source

The data used for this study are the Botswana AIDS Impact Survey (BAIS) II, a nationally representative sample survey conducted by the Central Statistics Office (CSO) and National AIDS Coordinating Agency (NACA) in 2004. The survey was conducted between 12 February 2004 and 3I July 2004. The behavioural segment of the sample survey targeted household members 10 to 64 years old, while the biomarker segment of the survey targeted household members above the age of 18 months (Republic of Botswana, 2005).

Of the 8,275 households initially selected into the sample, $92 \%$ participated in the survey (Republic of Botswana, 2005). There were 15,878 individuals who were successfully interviewed, giving a response rate of 93 per cent. 24,756 people aged 18 months and above were eligible for the HIV test and of these, 15,161 provided specimen. The participation rate for the HIV test was 61 per cent (Republic of Botswana, 2005).

\section{Study sample}

The current study relies on data provided by young people aged $10-24$ years in 2004. The sample for the current analysis is limited to all young people who completed the individual questionnaire of the Botswana AIDS Impact Survey II and had had sexual intercourse at the time of the survey.

\section{Measurement of variables}

The primary outcome variables examined are: whether the respondents have used condoms during their last sexual encounter (Conduse) and whether the 
respondent had sexual intercourse with one or no person in the past 12 months (Multipart). The question on whether the respondents have used condoms during their last sexual encounter was coded $\mathrm{I}$ if the response was yes (which was considered safe sexual behaviour) or 0 if it was no. Respondents who stated that they had sexual intercourse with one or no person in the past 12 months (which was considered safe sexual behaviour) were coded as I or 0 if they had more than one partner. These are behavioural indicators that measure individual young people's actions which directly determine their risk of exposure to HIV infection. The assumption is that young people who used a condom during their last sexual intercourse or had sex with no more than one person had a positive attitude to safer sex were not inhibited by their significant others in adopting the positive behaviours, and felt empowered to adopt the positive behaviour of adopting safe sexual behaviours, resulting in a higher motivation for them to adopt safe sexual behaviours.

Initially, these variables were put together to create composite indices that capture knowledge of HIV prevention methods of HIV infection and no incorrect beliefs about HIV/AIDS. An attempt was made to create a knowledge composite index by lumping together two variables, (whether people believe they can reduce their chances of contracting HIV infection by using a condom correctly every time they have sex (Condconsist) and whether people believe they can reduce their chances of contracting HIV infection by having only one uninfected sex partner who has no other partners
(Fidelity)) to create a knowledge of HIV prevention methods index and another composite index of no incorrect beliefs about AIDS composed of the remaining four questions: do you think that a person can get infected with HIV/AIDS through mosquito bites (Mosquito)? Can a person get infected with HIV/AIDS by sharing a meal with a person who has HIV/AIDS (Sharemeal)? Can people get HIV/AIDS because of witchcraft (Witchcraft)? Is it possible for a healthy-looking person to have the AIDS virus (Healthlook)? A respondent must correctly reject misconceptions and must know that a healthy-looking person can transmit HIV to be included in the numerator of this indicator. This indicator was expected to provide a good picture of the level of false beliefs that may impede people's determination to act on correct knowledge.

In order to assess how well the above set of variables measured a single uni-dimensional latent construct, Cronbach's alpha was calculated. With regard to the first composite index of knowledge of prevention methods of HIV infection, Cronbach's alpha was 0.285 , indicating low internal consistency in the data. Regarding the internal consistency index for all four variables used in the no incorrect beliefs index, Cronbach's alpha was 0.379 , which suggested that the data were multi-dimensional. To check the multidimensionality of the data, factor analysis was performed. It became clear that the data were not uni-dimensional because two factors emerged from factor analysis, suggesting that the four items should not be combined to create a single index, but instead that two indi- 
ces should be created.

To solve the low internal consistency index (Cronbach's alpha = 0.3779) for the four-item index, another no incorrect belief index was constructed consisting of two variables (namely, whether HIV can be contracted through sharing meal with a person that is living with HIV/AIDS and whether HIV infection can be acquired through mosquito bites). In this case, Cronbach's alpha was slightly improved to 0.458 . It should be noted that Cronbach's alpha which is closer to I reflects higher internal consistency of the items. Since in most social science research, a Cronbach's alpha of at least 0.7 is considered "acceptable" (httpD www.ats.ucla.edu/stat/spss/faq/

alpha.html), the Cronbach's alphas obtained from the above composite indices are unacceptably low. The low Cronbach's alpha could be suggestive of the fact that these individual variables can not be lumped together as they do not measure the same concept. Therefore the researcher decided to use individual variables in the logistic regression analysis rather than composite indices.

The analysis examines the effects of seven independent variables (generally referred to as knowledge about HIV/ AIDS prevention and transmission methods) on the two outcome variables discussed earlier in this section. The seven variables are: (I) whether people believe there is anything that a person can do to prevent becoming infected with HIV virus (Canprevent); (2) whether people think they can reduce their chances of contracting HIV infection by using a condom correctly every time they have sex (Condconsist); (3) whether people think they can reduce their chances of contracting HIV infection by having only one uninfected sex partner who has no other partners (Fidelity); (4) whether the respondents think that a person can get infected with HIV/AIDS through mosquito bites (Mosquito); (5) whether a person believes s/he can get infected with HIV/ AIDS by sharing a meal with a person who has HIV/AIDS (Sharemeal); (6) whether people believe they can get HIV/AIDS because of witchcraft (Witchcraft); and (7) whether they think it is possible for a healthy-looking person to have the AIDS virus (Healthlook).

Another set of variables relates to socio-demographic variables which were introduced as controls and includes the respondent's age (Age), educational attainment (Education), marital status (Marstat), and place of residence (Residence). The educational attainment is restricted to primary and secondary and over because there were very few cases of young people who had no education and the majority were either in primary or secondary schools. Marital status is categorised as currently in union or not in union. Currently in union includes those who were currently married or living together whereas not in union includes those who are separated, divorced, widowed and never married.

Statistical analysis

Because respondents to the BAIS II were chosen with differing probabilities of selection, the data had to be weighted to obtain unbiased estimates of the parameters of interest in the study. The analysis is performed in three parts. First, the characteristics of the sample are described. Second, 
cross-tabulations between dependent and independent variables are performed to assess the associations. Finally, logistic regression analysis is used to estimate the influence of each of the knowledge variables on the selected measures of behaviour change variables (condom use and having had sex with no more than one person in the past year), controlling for the sociodemographic variables such as age, education, marital status and place of residence.

Because our dependent variables are categorical, the most appropriate method for estimating the influence of knowledge variables on behaviour change variables is logistic regression analysis. Dogistic regression analysis is used because it provides an interpretable linear model for a binary dependent variable and also allows the testing of the significance of a given predictor while controlling for all other predictors in the model. All analyses are conducted using SPSS 15.0 computer software.

Study limitations

One of the major study limitations is the fact that the study uses secondary data, thus some of the variables that the researcher would have wished to include in the analysis such as self-efficacy variable were not available from the data. Second, the information used in the analysis was self-reported and as such subject to reporting errors and biases. Since the study used to obtain the data was cross-sectional, it is difficult to establish cause-and-effect relationships in the variables under study. The interpretation of the results is therefore limited to associations between variables rather than causeand-effect relationships.

\section{Results}

\section{Sample characteristics}

Table I presents the percentage distribution of young people in the study sample by selected characteristics according to sex. Overall, 77 per cent of the young people were aged between 20-24 years. The mean age of the studied young people was 21 years. In terms of sex distribution, the majority of the young people were females, aged 20-24 years. About four out of five of the young people had attained secondary education, followed by those with primary education. The average time of education completed by young people was 10 years. Most of the young people, particularly the males, had never been married, although a third of them were cohabiting. The mean age at sexual debut was 18.2 years. 
Table I Percentage distribution of young people in Botswana by sex and selected characteristics, BAIS - II 2004

\begin{tabular}{|c|c|c|c|}
\hline Characteristic & $\begin{array}{c}\text { Male } \\
(N=4,436)\end{array}$ & $\begin{array}{c}\text { Female } \\
(N=14,467)\end{array}$ & $\begin{array}{c}\text { Total } \\
(\mathrm{N}=18,903)\end{array}$ \\
\hline \multicolumn{4}{|l|}{ Age } \\
\hline $\begin{array}{l}10-14 \\
15-19 \\
20-24\end{array}$ & $\begin{array}{l}1.2 \\
15.6 \\
83.2\end{array}$ & $\begin{array}{c}0.3 \\
24.6 \\
75.1\end{array}$ & $\begin{array}{c}0.5 \\
22.5 \\
77.0\end{array}$ \\
\hline Mean age (years) & 21.7 & 21.4 & 21.5 \\
\hline \multicolumn{4}{|l|}{ Educational level } \\
\hline $\begin{array}{l}\text { Non-formal } \\
\text { Primary } \\
\text { Secondary } \\
\text { Higher }\end{array}$ & $\begin{array}{c}0.0 \\
16.1 \\
74.1 \\
9.8\end{array}$ & $\begin{array}{c}0.9 \\
10.0 \\
82.4 \\
6.8\end{array}$ & $\begin{array}{c}0.7 \\
11.3 \\
80.6 \\
7.4\end{array}$ \\
\hline Mean years of education completed & 10.0 & 9.9 & 9.9 \\
\hline \multicolumn{4}{|l|}{ Marital status } \\
\hline $\begin{array}{l}\text { Married } \\
\text { Пiving together } \\
\text { Never married }\end{array}$ & $\begin{array}{c}0.0 \\
17.9 \\
82.1\end{array}$ & $\begin{array}{c}0.6 \\
37.4 \\
62.0\end{array}$ & $\begin{array}{c}0.4 \\
32.8 \\
66.7\end{array}$ \\
\hline \multicolumn{4}{|l|}{ Place of residence } \\
\hline $\begin{array}{l}\text { Rural } \\
\text { Urban }\end{array}$ & $\begin{array}{l}36.3 \\
63.7\end{array}$ & $\begin{array}{l}36.9 \\
63.1\end{array}$ & $\begin{array}{l}36.8 \\
63.2\end{array}$ \\
\hline Percent with multiple sexual partners & 37.5 & 21.9 & 21.6 \\
\hline Mean number of sexual partners & 1.4 & 1.1 & 1.2 \\
\hline Percent used condom at last sex & 87.8 & 68.0 & 72.7 \\
\hline Mean age at first sexual intercourse & 18.7 & 18.0 & 18.2 \\
\hline $\begin{array}{l}\text { Percent who ever had sexual partner who } \\
\text { was } 10 \text { years older or younger }\end{array}$ & 7.9 & 22.9 & 19.4 \\
\hline
\end{tabular}

Over a fifth of the young people reported having had multiple sexual partners. Another fifth of the young people reported having had sexual intercourse with a person 10 years older or younger than themselves. It should also be noted that 73 percent of the young people stated that they had used condoms during their last sexual encounter, particularly the males.
About $23 \%$ of young people reported having had sex with more than one partner without using condom during intercourse (table not shown). It is noteworthy that men were almost twice as likely to have had multiple partners, much more likely to use condoms, and much less likely to have partners with a large age difference.

In Table 2, the study examined how 
different independent variables were related to young people's condom use in the last sexual encounter and having had sexual intercourse with at most one partner in the past year.

Table 2 Percentage of young people in Botswana giving specified responses to measures of knowledge of HIV transmission and prevention, Botswana 2004

Knowledge about HIVZAIDS prevention and transmission

\section{Sexual behaviours}

\begin{tabular}{|c|c|c|c|}
\hline \multicolumn{4}{|c|}{ Conduse $(\mathrm{N}=14922)$} \\
\hline & & $\begin{array}{c}\text { Condom } \\
\text { used }\end{array}$ & $\begin{array}{c}\text { No condom } \\
\text { used }\end{array}$ \\
\hline Can prevent & Yes & $\begin{array}{l}73.8 \\
65.0\end{array}$ & $\begin{array}{l}26.2 \\
35.0\end{array}$ \\
\hline Condconsist & Yes & $\begin{array}{l}73.5 \\
60.0\end{array}$ & $\begin{array}{l}26.5 \\
40.0\end{array}$ \\
\hline Fidelity & Yes & $\begin{array}{l}73.3 \\
69.5\end{array}$ & $\begin{array}{l}26.7 \\
30.5\end{array}$ \\
\hline Mosquito & Yes & $\begin{array}{l}78.1 \\
70.0\end{array}$ & $\begin{array}{l}21.9 \\
30.0\end{array}$ \\
\hline Sharemeal & Yes & $\begin{array}{l}77.1 \\
72.1\end{array}$ & $\begin{array}{l}22.9 \\
27.9\end{array}$ \\
\hline Witchcraft & Yes & $\begin{array}{l}69.3 \\
72.5\end{array}$ & $\begin{array}{l}30.7 \\
27.5\end{array}$ \\
\hline Healthlook & Yes & $\begin{array}{l}72.6 \\
78.6\end{array}$ & $\begin{array}{l}27.4 \\
21.4\end{array}$ \\
\hline & $r t(N=\mid 492 I)$ & & \\
\hline Canprevent & Yes & $\begin{array}{c}\text { Had } \\
\text { intercourse } \\
\text { with } 0 \text { or I } \\
\text { person }\end{array}$ & $\begin{array}{c}\text { Had } \\
\text { intercourse } \\
\text { with more than } \\
\text { I person }\end{array}$ \\
\hline Condconsist & Yes & $\begin{array}{l}85.1 \\
50.4\end{array}$ & $\begin{array}{l}14.9 \\
49.6\end{array}$ \\
\hline Fidelity & Yes & $\begin{array}{l}84.8 \\
70.8\end{array}$ & $\begin{array}{l}15.2 \\
29.2\end{array}$ \\
\hline Mosquito & Yes & $\begin{array}{l}83.9 \\
85.7\end{array}$ & $\begin{array}{l}16.1 \\
14.3\end{array}$ \\
\hline Sharemeal & Yes & $\begin{array}{l}87.7 \\
81.8\end{array}$ & $\begin{array}{l}12.3 \\
18.2\end{array}$ \\
\hline
\end{tabular}




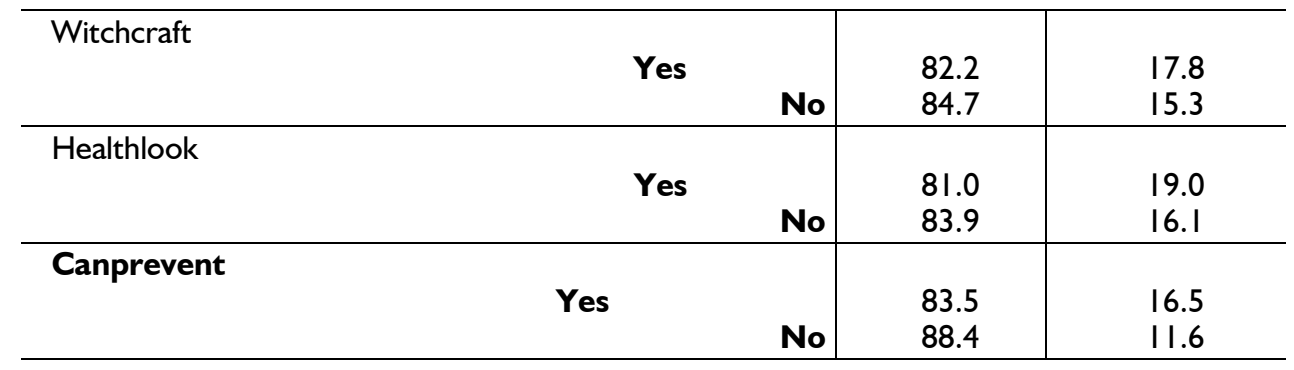

The results from Table 2 showed that overall condom was used by roughly three-quarters of the young people. Young people who knew that something can be done to prevent becoming infected with HIV (74\%), those who knew that people can reduce their chances of getting HIV infection by using a condom correctly every time they have sex $(74 \%)$, those who knew that having only one uninfected sex partner who has no partners can reduce chances of getting HIV infection (73\%), and those who knew that one cannot get HIV/AIDS because of witchcraft $(73 \%)$ were associated with the likelihood of having used condoms during the last sexual intercourse. It should however be noted that the differences were rather small, suggesting that other reasons also play a part in deciding condom use.

With regard to having had sex with at most one partner in the past year, young people who knew that something can be done to prevent becoming infected with HIV (85\%), those who knew that people can reduce their chances of getting HIV infection by using a condom correctly every time they have sex $(85 \%)$ and those who knew that one cannot get HIV/AIDS because of witchcraft (84\%) were associated with the likelihood of having had sex with no more than one partner in the past year. However, the results also showed that young people who stated that one can reduce their chances of getting HIV infection by having only one uninfected sex partner who has no other partners, those who thought that a person can get infected with HIV by sharing a meal with a person who has HIV/AIDS and those who thought that it is not possible for a healthy-looking person to have HIV were associated with the likelihood of having had sex with no more than one partner in the past year

The problem with bivariate analysis is that some of the variables that could be confounding the relationship between knowledge variables and safe sex behaviours have not been controlled for. To take care of this contamination, a logistic regression analysis was used to assess the independent effect of each of the knowledge variables on behavioural variables, controlling for socio-demographic factors such as age, education, marital status and place of residence.

Table 3 presents the results of the logistic regression analysis that shows the likelihood of condom use at the last sexual intercourse by young people. The results show that young people who knew that something can be done to prevent becoming infected with HIV were 2.6 times more likely to report having used a condom during their last sexual intercourse than those who did 
not know that something can be done to prevent becoming infected with HIV. This relationship is statistically significant at $95 \%$ level. In addition, young people who knew that having only one uninfected sex partner who has no partners can reduce chances of getting HIV infection were 1.9 times more likely to report that they had used a condom during their last sexual encounter than those who did not know that having only one uninfected sex partner who has no partners can reduce chances of getting HIV infection and the relationship is statistically significant at $95 \%$ level.

Table 3 Odds ratios that condom was used the last time young people had sexual intercourse, Botswana, BAIS -II, 2004

\begin{tabular}{|c|c|c|}
\hline Characteristic & \multirow{2}{*}{ Odds ratio } & \multirow{2}{*}{$95 \%$ C.1. for EXP (B) } \\
\hline Canprevent & & \\
\hline Yes & $2.588 * * * *$ & $($ (I. 792,3.736) \\
\hline No & 1.000 & - \\
\hline Condconsist & & \\
\hline Yes & 0.992 & $(0.832,1.183)$ \\
\hline No & 1.000 & - \\
\hline \multirow[t]{2}{*}{ Fidelity } & & \\
\hline & $1.942 * * *$ & $(1.725,2.186)$ \\
\hline No & 1.000 & - \\
\hline \multirow[t]{2}{*}{ Mosquito } & & \\
\hline & 1.000 & - \\
\hline No & $0.419 * * * *$ & $(0.377,0.465)$ \\
\hline \multirow[t]{2}{*}{ Sharemeal } & & \\
\hline & 1.000 & - \\
\hline No & 0.923 & $(0.819,1.039)$ \\
\hline Witchcraft & & \\
\hline Yes & 1.000 & - \\
\hline No & I.47I $* * * *$ & $(1.292,1.675)$ \\
\hline \multirow[t]{2}{*}{ Healthlook } & & \\
\hline & $0.425 * * * *$ & $(0.332,0.545)$ \\
\hline No & 1.000 & - \\
\hline Canprevent & & \\
\hline Yes & 1.000 & - \\
\hline No & I.97| $* * * * *$ & $(1.772,2.931)$ \\
\hline Educ & & \\
\hline Primary & 1.000 & - \\
\hline Secondary plus & I. $605 *$ **** & $(1.335,1.930)$ \\
\hline Marstat & & \\
\hline Currently in union & 1.000 & - \\
\hline Not in union & $\mathrm{I} .48 \mathrm{I}^{* * * *}$ & $(1.343,1.635)$ \\
\hline Residence & 1.027 & $(0.927,1.137)$ \\
\hline Rural & 1.000 & - \\
\hline \multirow{2}{*}{$\begin{array}{l}\text { Predicted correctly (\%) } \\
-2 \text { log likelihood }\end{array}$} & 73.2 & - \\
\hline & I2364.97| & - \\
\hline$N=$ & 176 & - \\
\hline \multicolumn{3}{|c|}{ Note: $* * * \mathrm{p}<0.001,{ }^{* *} \mathrm{p}<0.01,{ }^{*} \mathrm{p}<0.05 .(\mathrm{r})=$ reference category. - = Not applicable. } \\
\hline \multicolumn{3}{|c|}{$\begin{array}{l}\text { C.I. }=\text { Confidence interval. EXP }(B)=\text { Exponent of beta }(\text { coefficient }) . \text { BAIS }- \text { II }=\text { Botswana } \\
\text { AIDS Impact Survey II. }\end{array}$} \\
\hline
\end{tabular}

Knowledge that a person cannot get bites, that a person cannot get HIV infected with HIV through mosquito infection by sharing a meal with a per- 
son living with HIV/AIDS, and that it is possible that a healthy-looking person can have HIV were significantly associated with decreased likelihood of reporting that they had used a condom during their last sexual encounter than those who did not know. These relationships are statistically significant at $95 \%$ level.

Table 4 Odds ratios that young people have had sexual intercourse with not more than one partner in the past year, Botswana, BAIS -II, 2004

\begin{tabular}{|c|c|c|c|}
\hline \multicolumn{2}{|c|}{ Characteristic } & \multirow{2}{*}{$\begin{array}{l}\text { Odds ratio } \\
2.193^{* * * *} \\
1.000\end{array}$} & \multirow{2}{*}{$\begin{array}{c}\text { 95\% C.I. for EXP (B) } \\
(1.457,3.302) \\
-\end{array}$} \\
\hline Canprevent & Yes & & \\
\hline Condconsist & Yes & $\begin{array}{l}0.979 \\
1.000\end{array}$ & $\begin{array}{c}(0.797, \mid, 202) \\
-\end{array}$ \\
\hline Fidelity & No & $\begin{array}{l}0.755^{*} * \\
1.000\end{array}$ & $\begin{array}{c}(0.632,0.903) \\
-\end{array}$ \\
\hline Mosquito & Yes & $\begin{array}{c}1.000 \\
0.639 * * * * 1\end{array}$ & $(0.563,0.725)$ \\
\hline Sharemeal & Yes & $\begin{array}{l}1.000 \\
\text { I.598*** }\end{array}$ & $(1.382,1.848)$ \\
\hline Witchcraft & Yes & $\begin{array}{c}1.000 \\
1.617^{* * * *}\end{array}$ & $(1.382,1.892)$ \\
\hline Healthlook & Yes & $\begin{array}{l}0.757 \\
1.000\end{array}$ & $\begin{array}{c}(0.56 I, I .02 I) \\
-\end{array}$ \\
\hline Age & $20-24$ & $\begin{array}{c}1.000 \\
0.568^{*} * * *\end{array}$ & $\begin{array}{c}- \\
(0.495,0.652)\end{array}$ \\
\hline Educ & $\begin{array}{l}\text { Primary } \\
\text { Secondary plus }\end{array}$ & $\begin{array}{c}1.000 \\
1.463^{*} *\end{array}$ & $(1.151,1.860)$ \\
\hline Marstat & $\begin{array}{r}\text { Currently in union } \\
\text { Not in union }\end{array}$ & $\begin{array}{c}1.000 \\
0.163^{* * * *}\end{array}$ & $(0.138,0.192)$ \\
\hline Residence & Rural & $\begin{array}{c}0.593 * * * \\
1.000\end{array}$ & $\begin{array}{c}(0.518,0.678) \\
-\end{array}$ \\
\hline $\begin{array}{l}\text { Predicted correctly (\%) } \\
-2 \text { log likelihood } \\
N=\end{array}$ & & $\begin{array}{c}85.4 \\
8518.234 \\
176\end{array}$ & $\begin{array}{l}- \\
- \\
-\end{array}$ \\
\hline
\end{tabular}

Note: $* * * p<0.00 I,{ }^{*} * p<0.0 I,{ }^{*} p<0.05 .(r)=$ reference category. $-=$ Not applicable.

C.I. = Confidence interval. EXP (B) = Exponent of beta (coefficient). BAIS - II = Botswana AIDS Impact Survey II. 
The results of the regression analysis of the factors associated with having had sexual intercourse with no more than one person in the past year are presented in Table 4. The results show that young people who knew that something can be done to prevent becoming infected with HIV were 2.2 times more likely to report having had sexual intercourse with not more than one person in the past year than those who did not know that something can be done to prevent becoming infected with HIV. Knowing that a person cannot get infected with HIV by sharing a meal with a person who has HIVIAIDS (OR $=\mathrm{I} .6$ ) and that people cannot get $\mathrm{HIV} /$ AIDS because of witchcraft $(O R=1.6)$ was significantly associated with the likelihood of having had sex with not more than one person compared with those who did not know.

The results also show that young people who knew that people can reduce their chances of getting HIV/ AIDS by having only one uninfected sex partner $(O R=0.755)$ and knew that a person cannot get infected with HIV through mosquito bites $(O R=0.639)$ were significantly associated with the decreased likelihood of having had sex in the past year with not more than one person.

The results from both bivariate and multivariate analyses indicate that a consistent and significant predictor of safe sex behaviours among young people is the knowledge that something can be done to prevent becoming infected with HIV. In the multivariate analysis, knowledge that people cannot get HIV because of witchcraft is significantly more likely to report safe sexual behaviours whilst knowledge that a person cannot get infected with HIV through mosquito bites is significantly associated with decreased odds of reporting safe sexual behaviours.

\section{Discussion}

The study investigated the influence of correct knowledge about HIV/AIDS prevention and transmission methods on safe sexual behaviours among young people in Botswana using the Theory of Planned Behaviour. The Theory did not always show the expected linkages between intention, knowledge and the behaviours. The study found that young people who knew that something could be done to prevent HIV infection and those who knew that having monogamous sexual relations with uninfected partners had higher odds of using a condom. At the same time, the study showed that young people who knew that a person cannot get infected with HIV through mosquito bites, that a person cannot get HIV infection by sharing a meal with a person living with HIV/ AIDS, and that it is possible that a healthy-looking person can have HIV were significantly associated with decreased likelihood of reporting that they had used a condom during their last sexual encounter than those who did not know.

The fact that some of the results contradicted the hypothesized relationships should be understood in the context of the model used in the study. The TPB views behavioural, normative, and control beliefs as the sole determinants of intentions and behaviours. All other factors are viewed as external influences that act through their influence on these three constructs. The model does not acknowledge what the dyadic 
ecological expansion of the TBP postulates (Hutchison et. al., 2007). The dyadic ecological expansion acknowledges that (i) there are two individuals who are jointly engaged in the sexual risk behaviour of interest (e.g. a young girl and her male partner); (ii) individual partners may have different intentions regarding the behaviour (e.g. condom use), yet only one of these intentions will be enacted; and (iii) each individual partner's behavioural, normative, and control beliefs are significantly influenced by a number of proximal systems, particularly their families" (Hutchinson et. Al., 2007:37). The expanded version of the TPB highlights that there are multiple potential influences of young people's sexual risk beliefs, intentions and behaviours (lbid, 2007).

The fact that young people who knew that a person cannot get infected with HIV through mosquito bites, that a person cannot get HIV infection by sharing a meal with a person living with HIV/AIDS, and that it is possible that a healthy-looking person can have HIV were significantly associated with decreased likelihood of reporting that they had used a condom during their last sexual encounter than those who did not know may be explained by myths and misconceptions regarding HIV. Although young people are aware of the routes of transmission, Detamo (2007) found that $58.8 \%$ of people under the age of 25 harboured at least one misconception regarding HIV and AIDS. In addition, younger people tend to portray HIVAIDS-related stigma and discriminatory attitudes towards people living with HIV and AIDS (Пetamo, 2003). As the expanded version of the
TPB stipulates, an individual may have intentions to use condoms but may not end up doing so because of disapproval from their sexual partner or religious beliefs. The study also found that young people who knew that something can be done to prevent becoming infected with HIV, those who knew that a person cannot get infected with HIV by sharing a meal with a person who has HIV/AIDS, and those who knew that people cannot get HIV/AIDS because of witchcraft were significantly associated with the likelihood of having had sex with no more than one person. The results also showed that young people who knew that people can reduce their chances of getting HIV/AIDS by having only one uninfected sex partner and knew that a person cannot get infected with HIV through mosquito bites were significantly associated with the decreased likelihood of having had sex in the past year with not more than one person.

Overall, it is evident from the study that knowledge that something can be done to prevent becoming infected with HIV, that people cannot get HIV infection because of witchcraft and educational attainment of respondents were consistently predictors of safe sex behaviours among young people in Botswana. However, the thought that a person can get infected with HIV through mosquito bites was less likely to be associated with safe sex behaviours.

These unexpected results probably show that even though young people may be knowledgeable about HIV preventative measures, the measures may not necessarily be practiced possibly because their circumstances dictate 
unsafe sex behaviours. UNDP (2000) study in Botswana found that women and girls often are victims of men's risky sexual behaviour which includes the latter's reluctance to use condoms in sexual intercourse, their tendency to have multiple partners, as well as their perpetration of violent acts such as rape. Another study by UNAIDS/WHO, 2005) found that poverty and genderbased violence by men has made it difficult for females to negotiate safer sexual practices. All of these factors explain why sometimes young people may be knowledgeable on how to prevent themselves from getting the HIV virus but do not put into practice their knowledge.

Thus, in this sample, the results suggest that the assumption of many HIV/ AIDS prevention programmes that when young people have HIV/AIDS information they need, that is enough to make them practice safe sex is not necessarily true. Other researchers (UNICEF, undated) have argued that having the information is not enough as young people also need to develop "life skills" - the attitudes and negotiating capacity to put what they know into practice and to make informed choices about sex, drugs and other issues. UNICEF (undated) also argues that in addition, young people need affordable "youth-friendly" health services that are sensitive to gender issues and provide voluntary and confidential HIV testing and counselling, along with condoms and treatment for other sexually transmitted infections.

The findings of the study on the relationship between knowledge that something can be done to prevent becoming infected with HIV and con- dom use could be explained by the fact that young people who used a condom during their last sexual encounter were more likely to have used it because they knew that they could do something to prevent HIV infection. Thus there is a high correlation between knowing that something can be done to prevent HIV infection and condom use. An unexpected finding was that young people who knew that consistent condom use could be used to prevent HIV infection was not related to condom use during the last sexual intercourse. This reflects that HIV-related knowledge does not necessarily influence people's decisionmaking when it comes to sexual behaviours but something else. This suggests that condom use is explained by other reasons other than HIV-related knowledge. There is need to undertake a more detailed study where these other reasons could be explored. It is possible that one may have the knowledge of HIV prevention methods available including condom use and have the intention to use condoms, but their partners may refuse their use.

The study showed that unlike in other parts of the world, knowledge levels about HIV/AIDS transmission and prevention among young people are fairly high, which is consistent with other studies (Republic of Botswana, 2005). The Government of Botswana has increasingly emphasized the need for greater awareness and practice of three-pronged strategy to prevent HIV infection. This strategy is known as the $A B C$ approach - signifying abstinence, being faithful to a single partner and condom use (Bankole et. al, 2004). The intensive condom use promotion reflects the reality that most people 
begin sexual activity while in the adolescent stage. The Population Services International (PSI) - Botswana has also been particularly aggressive in the promotion of condom use. However, other HIV prevention strategies such as abstinence are not promoted to the same degree of intensity as condom use.

It is clear that although correct knowledge of HIV/AIDS prevention and transmission methods does not necessarily translate into safe sexual behaviours, some knowledge of HIV prevention and transmission methods among young people is associated with safe sexual behaviours. After all, knowledge of protective behaviours is a prerequisite to the adoption of safe sex behaviour. Young people must learn the facts before they become sexually active and the information needs to be regularly reinforced and built on. However, it should be noted that HIVrelated knowledge is not the only predictor of safe sexual behaviours. Other predictors are equally if not more important in explaining sexual behaviours. One such factor is the role played by the significant other (sexual partner) in making decisions regarding whether condoms are used or not. One may have the will and intention to use condoms, but if their partners are against their use, depending on their power relations, condoms may not be used even though they have knowledge about effective HIV prevention measures. These other variables which are not considered in this study may help to explain why the results of this study sometimes appear contradictory.

The Information, Education and Communication component of the HIV prevention strategy that focuses on
$A B C$ do not seem to translate into safer sex behaviours among young people. A research based on primary data is required to investigate why the $A B C$ approach does not seem to be working. This research should enable policy makers to find out what changes are needed and how to fashion the IEC strategies so that they reach people. Teaching HIV/AIDS in schools must be continued and intensified. It should also be noted that young people are not a homogeneous group and therefore information targeting young people should be age-appropriate and timely. They should also take into account socio-economic and cultural differences among young people. Various, appropriate sources of information should also be employed depending on who is being targeted for HIV prevention.

The Government of Botswana has recognised that the assumption that knowledge leads to positive action (Republic of Botswana, 2006) which underpins the Information, Education and Communication (IEC) is not necessarily true and therefore decided to develop and implement a National Strategy for Behavioural Change Interventions and Communications $(\mathrm{BCIC})$ for HIV and AIDS. The BCIC underlying assumptions are that: (i) individuals act in relation to their social environment based on their own perception and/or experience of rewards associated with specific behaviours; (ii) behaviours require the physical and emotional capacity to act and these capacities can be learned through education, modelling and guided practice; and (iii) individuals can be motivated and equipped to engage in specific behaviours (Republic of Botswana, 2006). 
The philosophy behind $\mathrm{BCIC}$ is very similar to the theory of planned behaviour discussed earlier in the paper. In this paper unfortunately, it was not possible to measure the perceptions of young people regarding condom use and having monogamous sexual relationship and what they thought about their peers reaction if they knew that they were using condom and having monogamous relationships. It was also not possible to measure whether they believed that they had the power and skills (self-efficacy) to decide on the use of condoms and monogamous relationships.

\section{Conclusions}

Further research is needed to explore the influence of attitudes, norms, control, intention and behaviour as articulated in the theory of planned behaviour by conducting both a qualitative and quantitative study. The study will enable the researcher to have a better understanding of how the young people's attitudes toward self-performance of behaviour, their perception of the social normative pressures or relevant others' beliefs about the behaviour and their self-efficacy influence the adoption of safer sex behaviours. This type of research is necessary if appropriate and effective interventions are to be designed to address young people's sexual risky behaviours.

\section{References}

Ajzen, I. From intentions to actions: A theory of planned behaviour. In J. Kuhl \& J. Beckmann (Eds). Action control from cognition to behaviour. 1985: II-39, Berlin, Germany.
Springer-Verlag.

Ajzen, I. Theory of Planned Behaviour. 2006. http[/people.umass.edu/aizen/ index.html

Ajzen, I. and Fishbein, M. Understanding attitude and predicting social behaviour. 1980. Englewood Cliffs, N.J.: Prentice-Hall.

Bankole, A., Singh, S., Woog, V. \& Wulf, D. Risk and protection $\square$ youth and HIV/AIDS in sub-Saharan Africa. 2004. New York, Allan Guttmacher Institute.

Http[Dwww.ats.ucla.edu/stat/spss/

faq/alpha.html

Hutchinson, MK., Jemmott, $\square S$. , Wood, EB., Hewitt, H., Kawha, F., Waldron, N., and Bonaparte, B. CultureSpecific Factors Contributing to HIV Risk Among Jamaican Adolescents. Journal of the Association of Nurses in AIDS Care. 2007. 18(2): 35-47.

Jemmott, $\square$ S. and Jemmott, JB. III and McCaffree, K. Making proud choices! A safer-sex approach to HIV/STD and teen pregnancy prevention. $200 \mathrm{I}$. Select Media, Inc. New York.

Zetamo, G. Prevalence of, and Factors Associated with, HIV/AIDS-related Stigma and Discriminatory Attitudes in Botswana. Journal of Health, Population and Nutrition 2003, 21 (4): 347- 357.

Пetamo, G. Misconceptions about HIV prevention and transmission in Botswana. African Journal of AIDS Research 2007, 6(2): 193-198.

Madden, TJ., Ellen, PS. and Ajzen, I. A comparison of the theory of planned behaviour and the theory of reasoned action. Personality and Social Psychology Bulletin. 1992. 18:39. 
Impact Survey II, Popular Report 2004. 2005. NACA, UNDP, ACHAP and CSO.

Republic of Botswana National Strategy for Behaviour Change Interventions and Communications for 2006. National AIDS Coordinating Agency. April.

UNAIDS/WHO AIDS Epidemic Update, 2005.

UNDP Towards an AIDS-free generation. 2000. Gaborone. UNDP. UNICEF, UNAIDS \& WHO Young people and HIV/AIDS $\square$ Opportunity in Crisis. 2002. UNICEF, UNAIDS \&
WHO.

UNICEF Prevention among young people. http[/www.unicef.org/aids/ index_preventiongyoung.html. Accessed on 10/07/2006.

\section{Acknowledgements}

The author wishes to acknowledge and sincerely thank the Central Statistics Office in the Ministry of Finance and Development Planning for allowing him to use the 2004 Botswana AIDS Impact Survey data set. 